\title{
hangar de madera
}

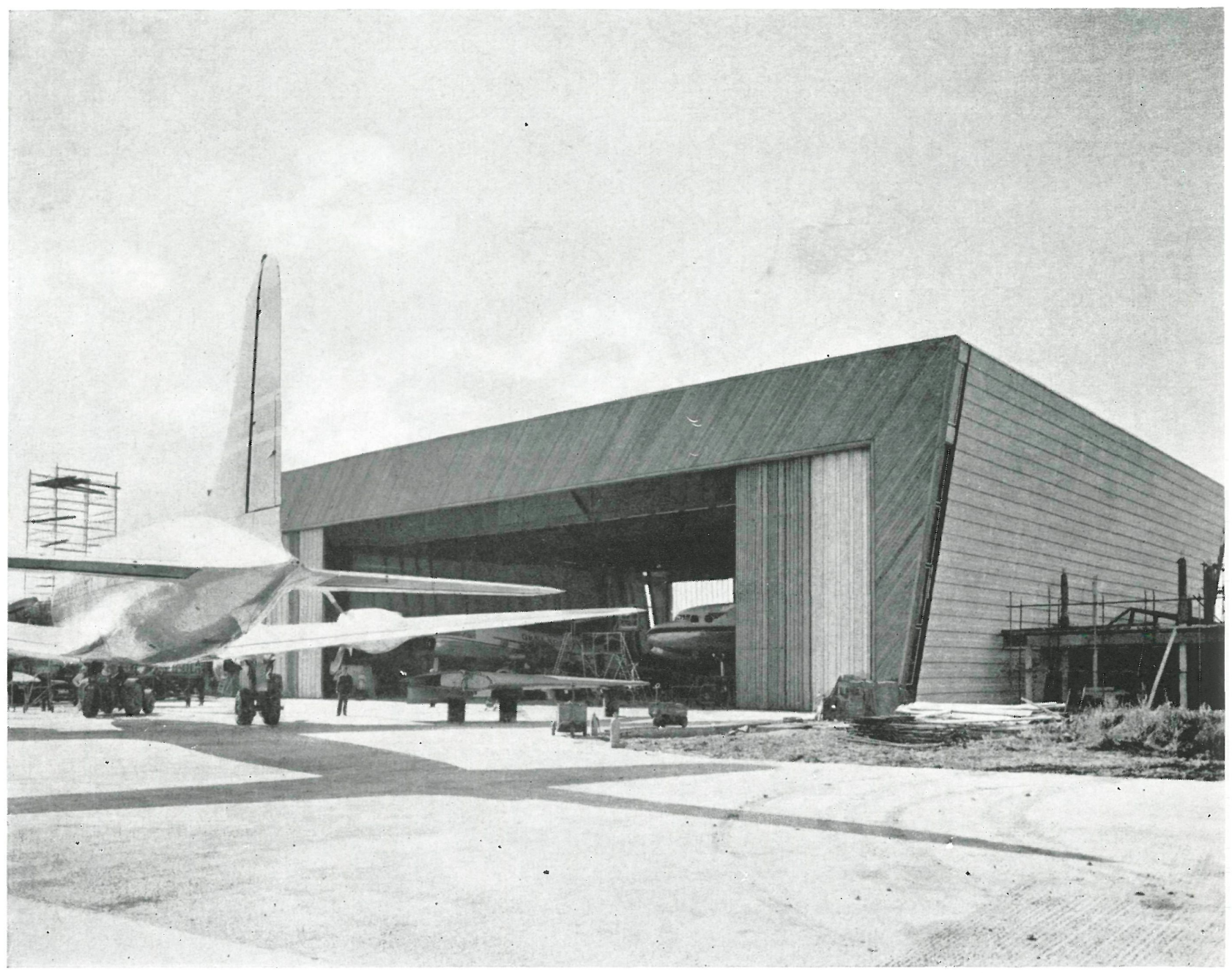

$544-28$

El nuevo hangar de madera, construído y proyectado por la empresa Beves and Co., tiene una luz libre de $45,7 \mathrm{~m}$. Su propietario, la Overseas Aviation Lte., lo utiliza para proteger los aviones que esta Compañía dispone en el aeropuerto de Gatwick (Inglaterra).

Después de considerar la solución metálica y estructura de hormigón se decidió proyectar el hangar basándose en una serie de pórticos paralelos, de madera en láminas y sin apoyos intermedios. Aunque economicamente presenta ventajas sobre otros materiales, su ligereza tenía gran importancia en este caso, pues el terreno del campo en que se halla situado no tiene gran capacidad resistente y, además, se contaba con gastos mínimos de conservación y una resistencia elevada contra el incendio. 


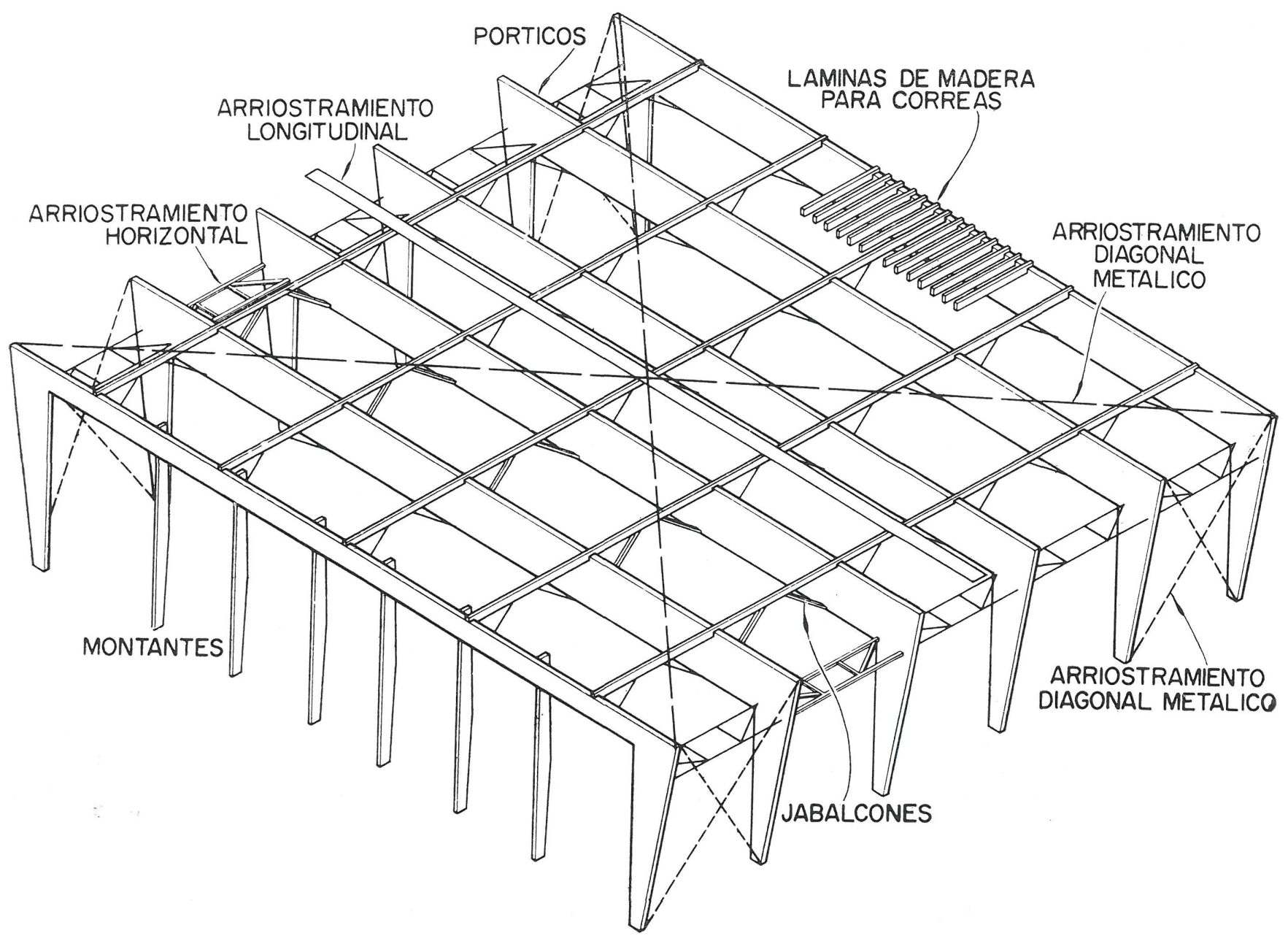

Todas las superficies exteriores se han revestido con tabla colocada diagonalmente, suficientemente madurada con el tiempo y acabada sin pintura, lo que también se ha traducido en una economía suplementaria.

La resistencia contra el incendio se ha estipulado en una hora de tiempo antes de llegar a la ruina de la estructura, período suficiente pará sacar el avión que pudiera encontrarse en su interior. Una estructura metálica no protegida no resiste este tiempo, dato importante que ha de considerarse al proyectar un hangar, ya que los aviones cuestan más que el propio hangar.

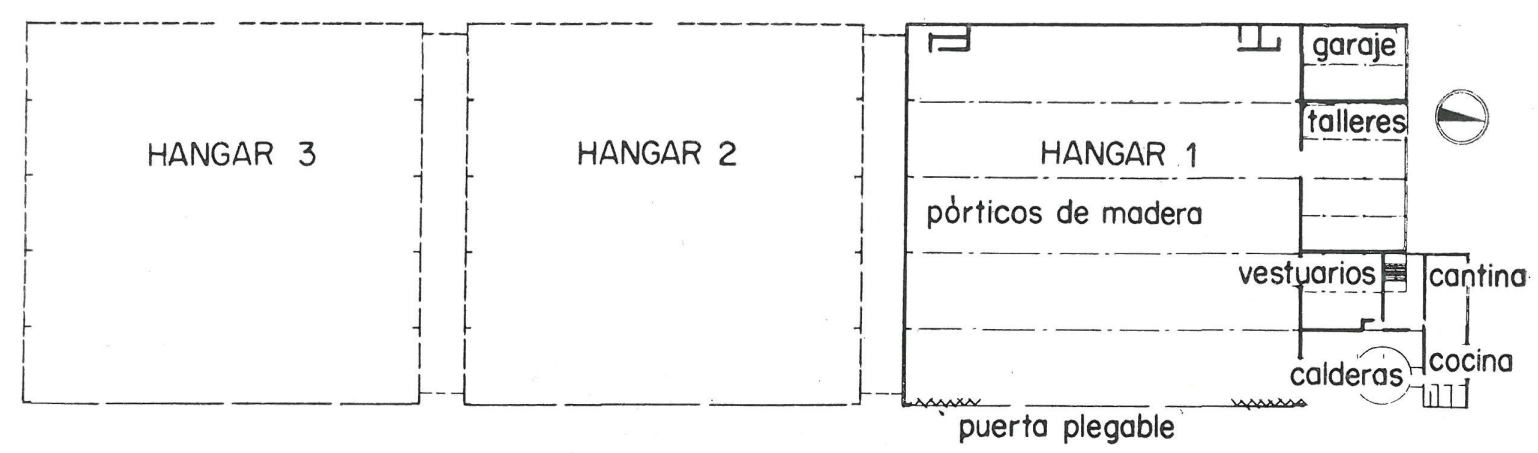




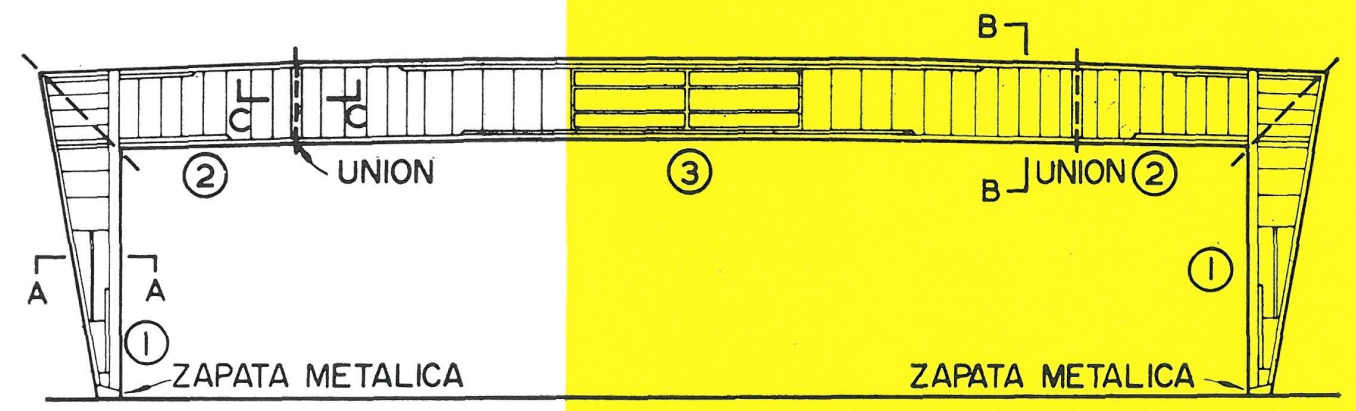

En el caso de iniciarse un incendio y extinguirlo antes de llegar a estados ruinosos, la estructura se presta a una rápida reparación.

La parte principal del hangar consiste en seis pórticos paralelos-de $51 \mathrm{~m}$ de longitud y $13 \mathrm{~m}$ de altura, espaciados a $9 \mathrm{~m}$, capaces de resistir a los esfuerzos del viento-, cubierta de placas de paja comprimida, aislantes y fieltro con asbestos, colocados sobre las correas, espaciadas a 0,90 metros.

Estas placas de cubierta se han revestido, en el intradós de la cubierta, con papel de asbestos de gran resistencia contra el incendio. Cada uno de los cabezales de los pórticos tiene una forma arqueada con canto máximo en la clave donde la flecha superior es de $45 \mathrm{~cm}$, y la inferior, de 22 . La cercha del fondo opuesta a la puerta metálica de entrada tiene soportes intermedios espaciados a $6 \mathrm{~m}$. El canto mínimo de esta cercha es de $1,5 \mathrm{~m}$, mientras que el de las otras es de 3,00 metros.

El método constructivo, llamado HB, consiste en formar vigas tipo doble $\mathrm{T}$, de cabezas de tabla y alma llena de dos capas de tabla colocada diagonalmente y formando dos direcciones rectangulares. La tabla o láminas que forman el alma se encolan y fijan a ras cabezas por medio de clavos. Al alma se le han acoplado listones verticales constituyendo elementos de rigidez. Para el cálculo de estas vigas se ha supuesto que las cabezas son capaces de resistir los esfuerzos de flexión, mientras que el alma absorbería los cortantes.

Para mejorar el montaje y preparación de cerchas éstas se han construído en cinco partes de fácil transporte y acoplamiento en obra. Dos de estas partes se solidarizan a pie de obra, se levantan y, finalmente, se cierran con un trozo recto que constituye la clave y que se eleva con una grúa. La unión entre este trozo de clave y el resto del pórtico se verifica con elementos metálicos, madera en láminas y puntas. Las bases de los montantes de los pórticos se acoplan a unas zapatas metálicas, provistas de pasadores soldados en su parte inferior, que se colocan en el interior de un hueco dejado en el hormigón y después de montada la cercha se anclan en dicho hueco que, para ello, se rellena de hormigón.

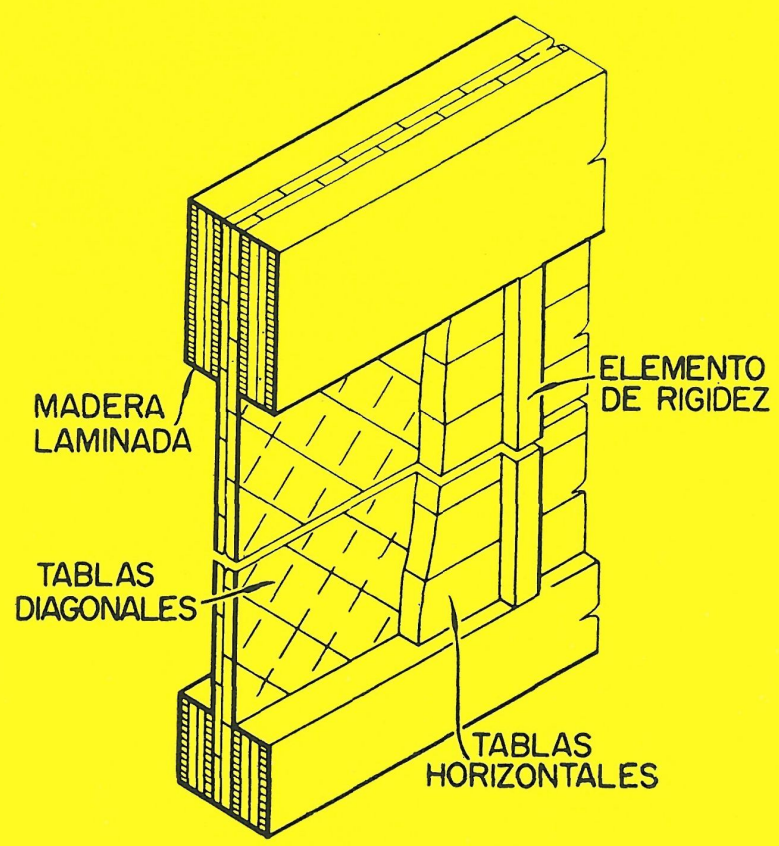

Section B-B

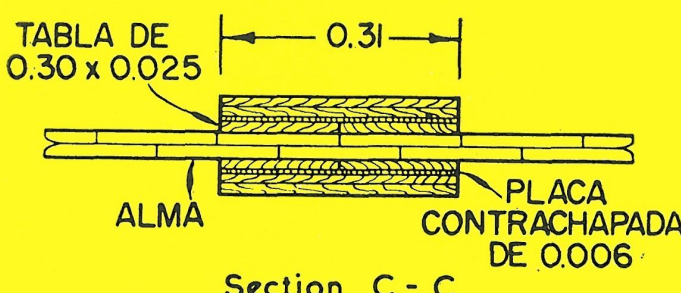

Section $C-C$ 


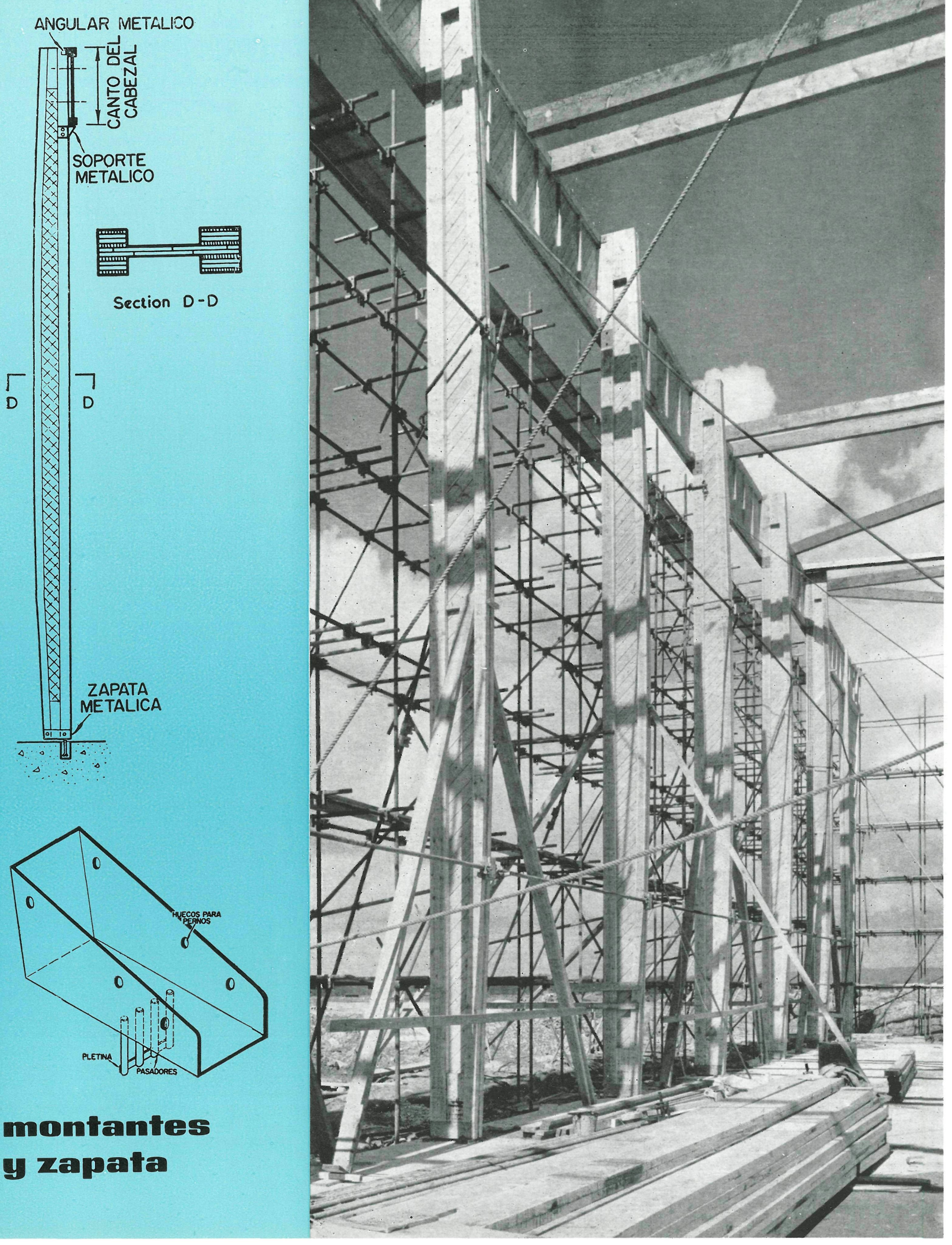




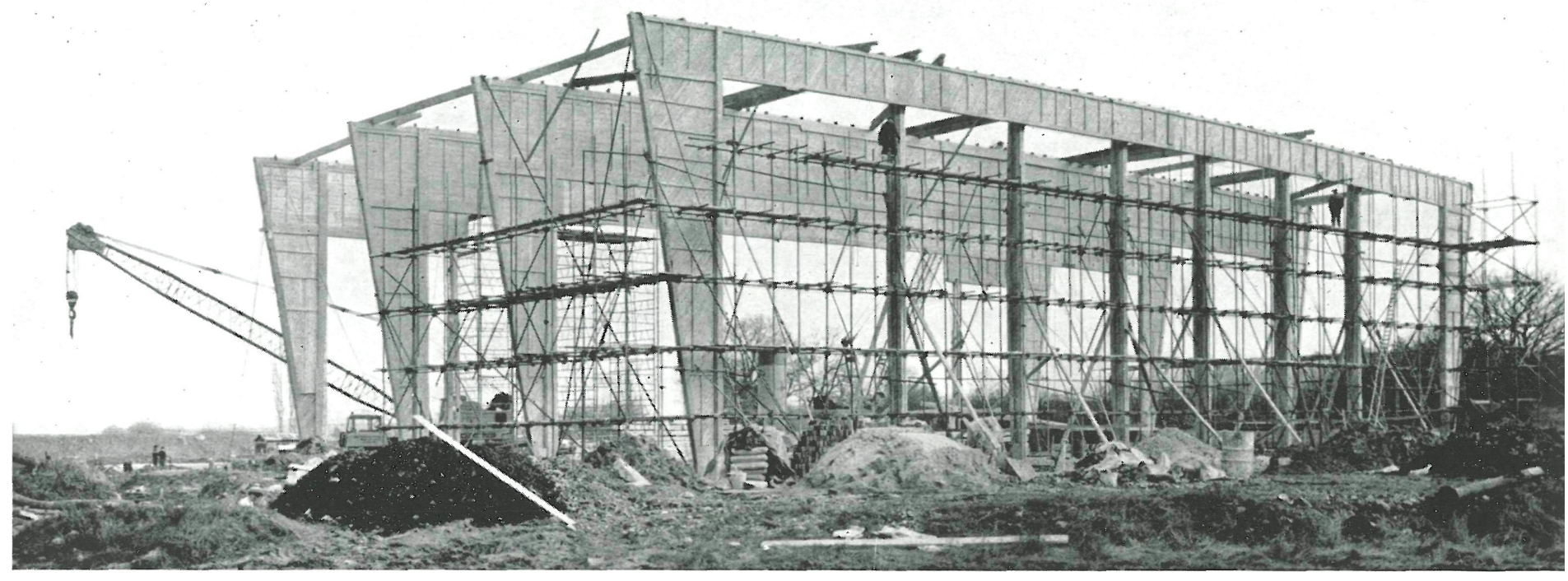

Las correas, de $0,30 \times 0,10 \mathrm{~m}$ de sección, se acoplan sobre las cabezas de las vigas por medio de elementos angulares y tornillos. La mayoría de las correas se componen de dos tablas encoladas y atornilladas.
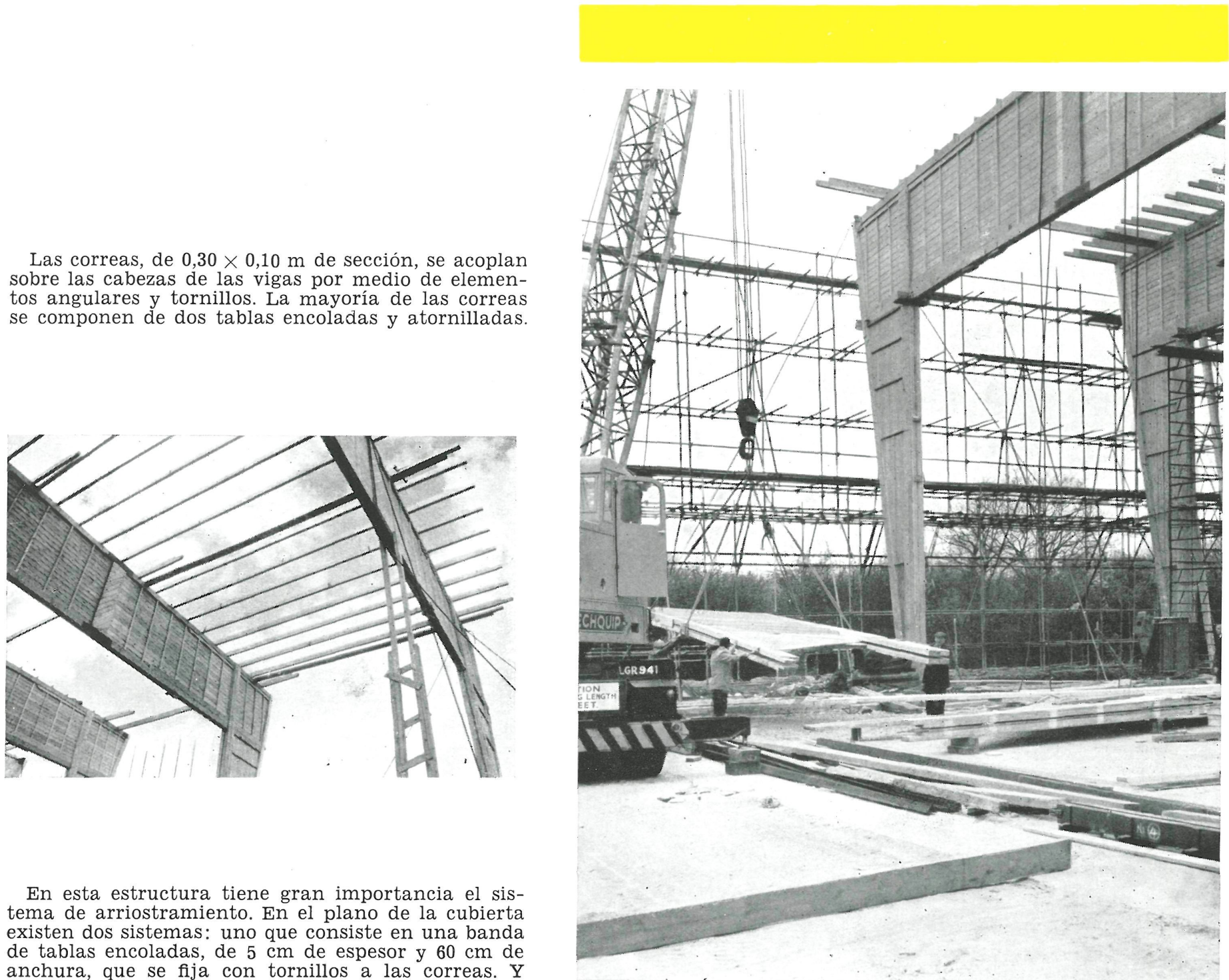

En esta estructura tiene gran importancia el sistema de arriostramiento. En el plano de la cubierta existen dos sistemas: uno que consiste en una banda de tablas encoladas, de $5 \mathrm{~cm}$ de espesor y $60 \mathrm{~cm}$ de anchura, que se fija con tornillos a las correas. Y 

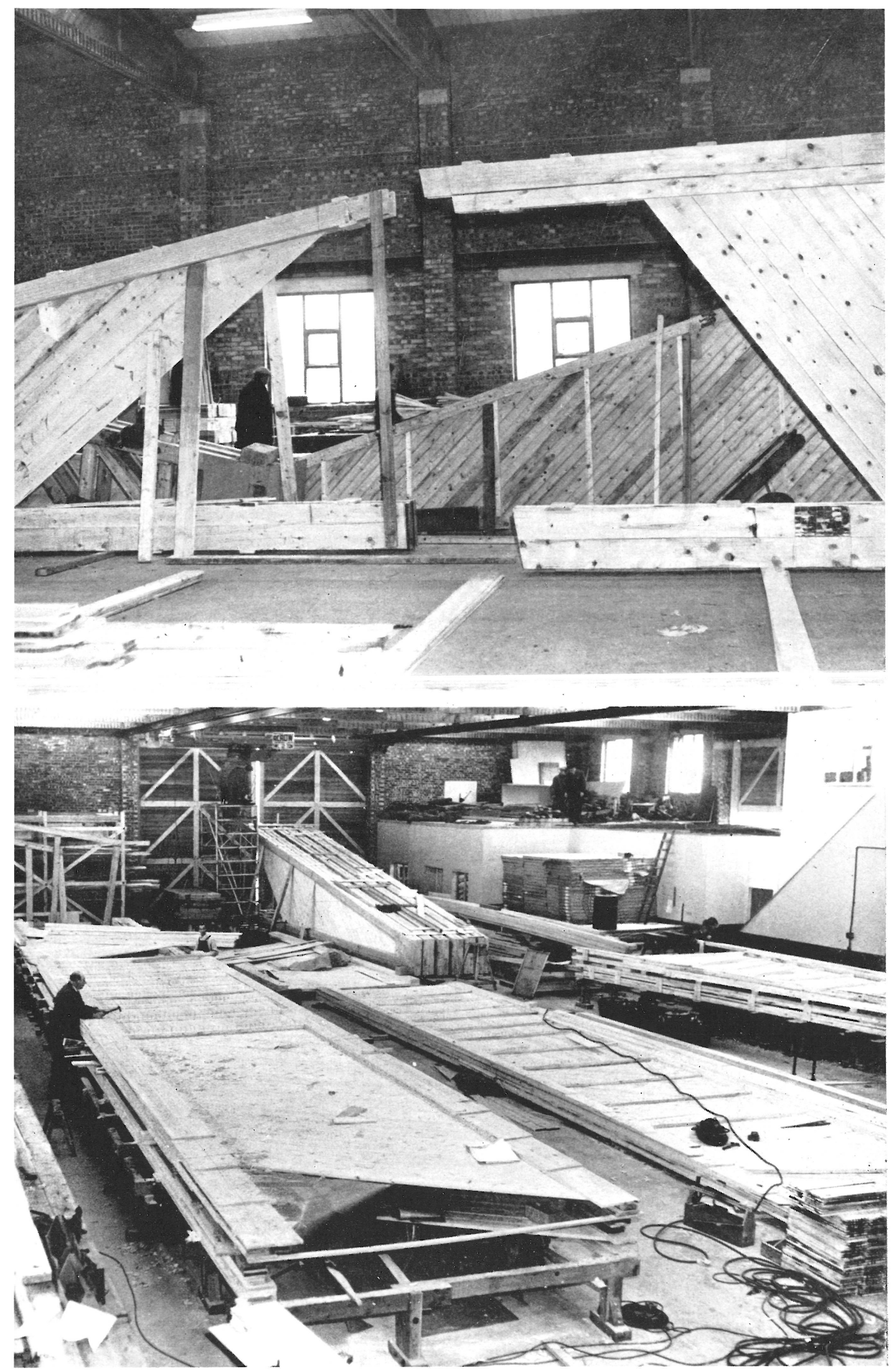


\section{montaje de pórticos}

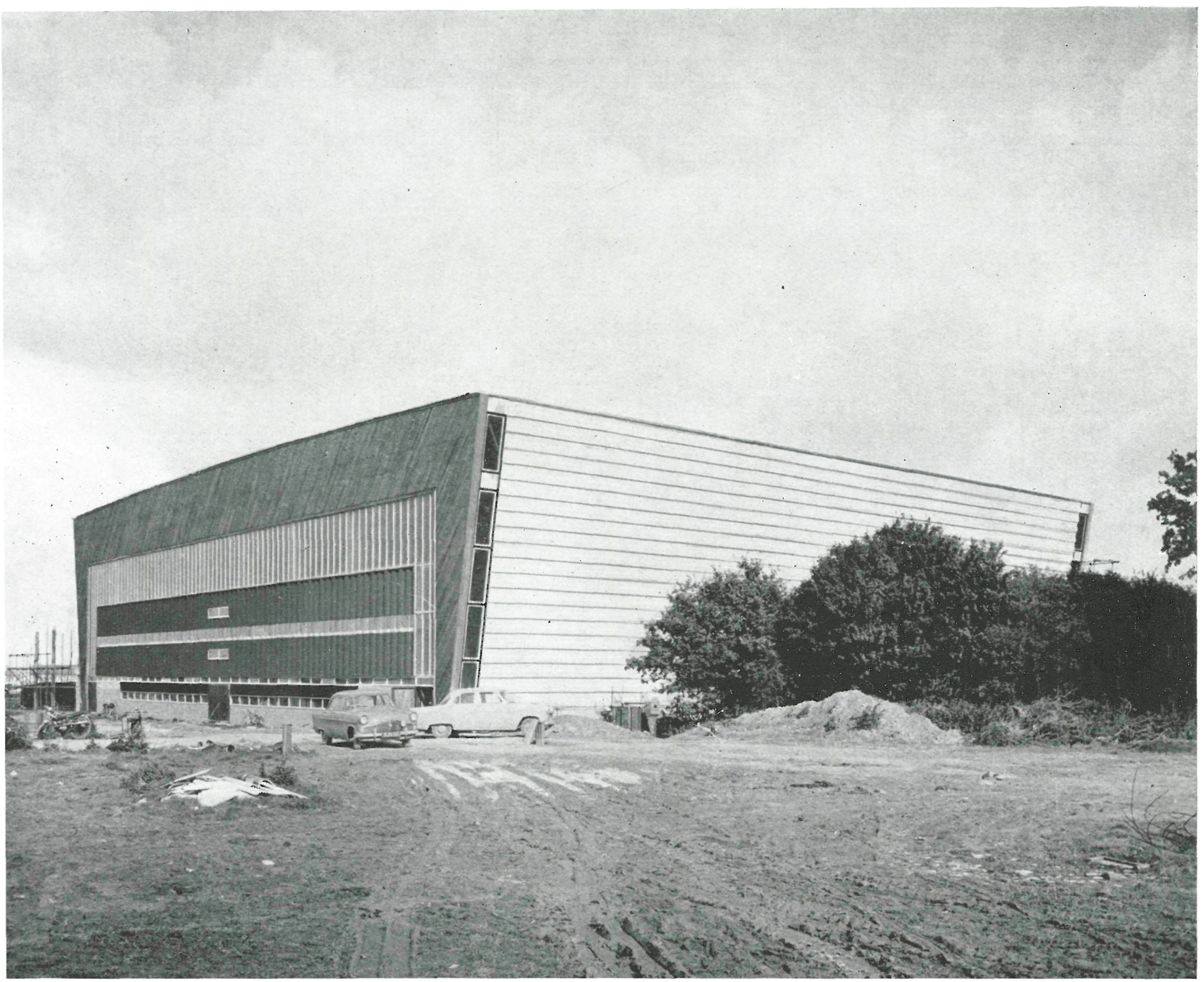

como su espesor es el mismo que el de las placas de paja comprimida, la superficie superior queda a ras con estas placas, y el segundo sistema, consiste en dos bandas metálicas que se extienden diagonalmente entre las cuatro esquinas del hangar.

Entre dos cerchas también va un arriostrado horizontal formando celosía, cuyo plano se halla más bajo que la cubierta, lo que reduce la altura libre expuesta a pandeo de los montantes, de los pórticos. Además de estos arriostramientos, se ha previsto otro adicional que es practicado entre las dos últimas cerchas, tanto de la parte anterior como posterior, y consiste en dos bandas metálicas, también dispuestas en diagonal, a lo que, finalmente, complementa unos listones que unen la cabeza inferior de los cabezales de los pórticos con las correas.

\section{Conclusiones}

La madera empleada en el hangar es de pino norte blanco, excepto las correas, que son de abeto Douglas. La cola es del tipo de formoaldehido constituyendo resina. Antes de someter la estructura a su propio peso pasa un gran período de tiempo de acomodación. 
El empleo de tabla permite un gran aprovechamiento de madera. La madera de buena calidad sólo se emplea en las partes que así lo exigen. La inclinación de los montantes hacia el exterior presenta la ventaja de que en caso de incendio caen al exterior.

Como el empleo de grandes estructuras de madera no es corriente en Inglaterra, no se puede sacar una línea arquitectónica general aplicable a estos tipos de construcción.

Estas estructuras se montan con mayor facilidad que las metálicas y se pueden ir preparando en el taller, lo que supone una gran reducción del tiempo de montaje. El tiempo previsto para la construcción de este hangar fue de dieciséis semanas, cuatro de ellas sólo para el montaje.

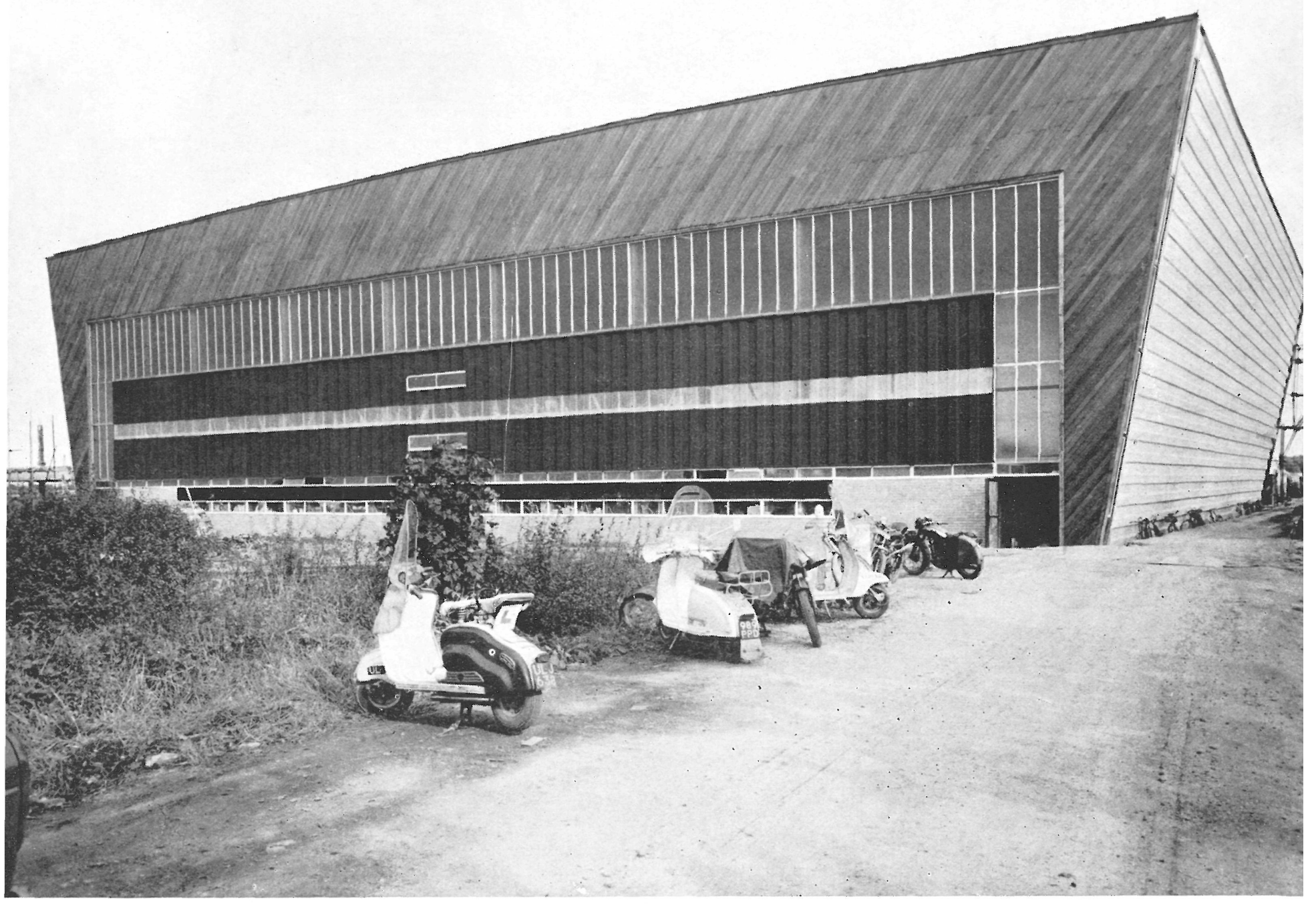

